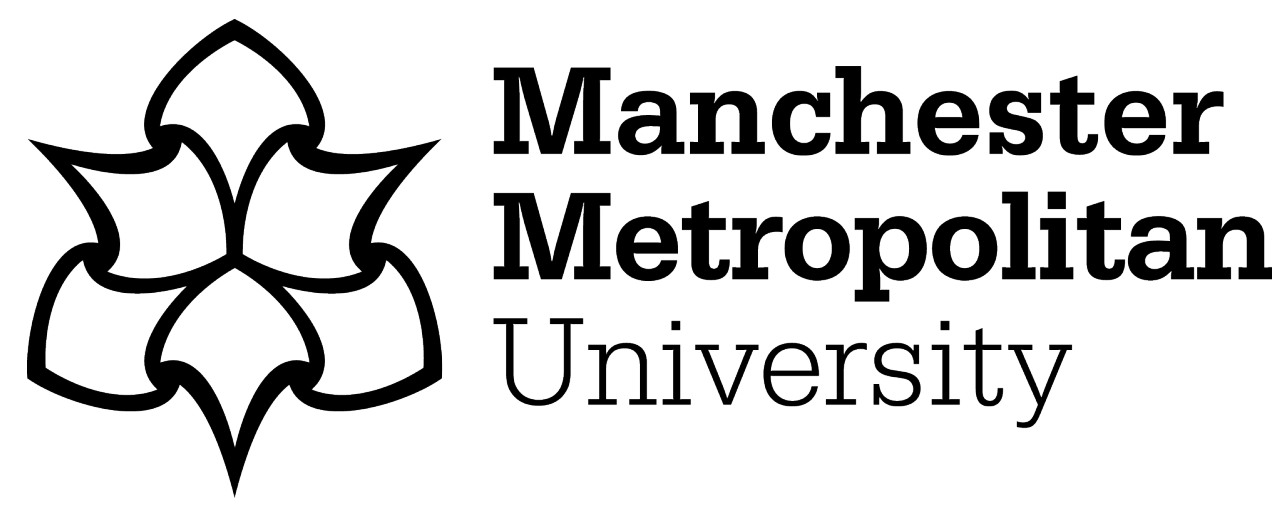

Donate-Robles, J, Liauw, Christopher and Martín-Martínez, JM (2014) Flow micro-calorimetry and diffuse reflectance Fourier transform infrared spectroscopy studies in filled polyurethane adhesives by using dimethyl adipate as a model compound. International Journal of Adhesion and Adhesives, 48. pp. 43-50. ISSN 0143-7496

Downloaded from: https://e-space.mmu.ac.uk/620993/

Version: Accepted Version

Publisher: Elsevier

DOI: https://doi.org/10.1016/j.jjadhadh.2013.09.027

Please cite the published version 


\section{Author's Accepted Manuscript}

Flow Micro-Calorimetry And Diffuse Reflectance Fourier Transform Infrared Spectroscopy Studies In Filled Polyurethane Adhesives By Using Dimethyl Adipate As A Model Compound

Jessica Donate-Robles, Christopher M. Liauw, José Miguel Martín-Martínez

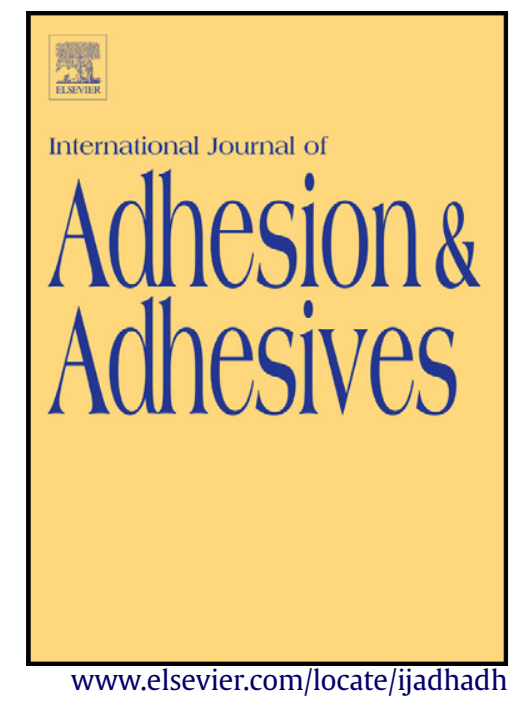

PII: S0143-7496(13)00164-4

DOI: $\quad$ http://dx.doi.org/10.1016/j.ijadhadh.2013.09.027

Reference: JAAD1415

To appear in: International Journal of Adhesion \& Adhesives

Accepted date: 4 July 2013

Cite this article as: Jessica Donate-Robles, Christopher M. Liauw, José Miguel Martín-Martínez, Flow Micro-Calorimetry And Diffuse Reflectance Fourier Transform Infrared Spectroscopy Studies In Filled Polyurethane Adhesives By Using Dimethyl Adipate As A Model Compound, International Journal of Adhesion \& Adhesives, http://dx.doi.org/10.1016/j.ijadhadh.2013.09.027

This is a PDF file of an unedited manuscript that has been accepted for publication. As a service to our customers we are providing this early version of the manuscript. The manuscript will undergo copyediting, typesetting, and review of the resulting galley proof before it is published in its final citable form. Please note that during the production process errors may be discovered which could affect the content, and all legal disclaimers that apply to the journal pertain. 


\title{
FLOW MICRO-CALORIMETRY AND DIFFUSE REFLECTANCE FOURIER TRANSFORM INFRARED SPECTROSCOPY STUDIES IN FILLED POLYURETHANE ADHESIVES BY USING DIMETHYL ADIPATE AS A MODEL COMPOUND
}

\author{
Jessica Donate-Robles ${ }^{(1)}$, Christopher M. Liauw ${ }^{(2)}$, José Miguel Martín-Martínez ${ }^{(1)^{*}}$ \\ ${ }^{(1)}$ Adhesion and Adhesives Laboratory, University of Alicante, 03080 Alicante, Spain \\ ${ }^{(2)}$ Centre for Materials Science Research, Manchester Metropolitan University, Chester \\ Street, Manchester M1 5GD, UK
}

${ }^{*}$ Corresponding author. Tel.: +34 965 903977; Fax: +34 965909416.

E-mail address: jm.martin@ua.es 


\section{ABSTRACT}

Interactions between nano-scale filler particles (precipitated calcium carbonate, carbon black and fumed silica) and model compounds (dimethyl adipate and butan-2-one) are quantified using flow micro-calorimetry (FMC) and diffuse reflectance Fourier transform infrared spectroscopy (DRFTIRS). Carbonyl groups of dimethyl adipate interact strongly with silanol groups on the fumed silica surface but weakly with the uncoated precipitated calcium carbonate. In general, higher surface area loading a high level of adsorption because of the nanofiller has more adsorption sites. Carbon black is an exception likely due to the less accessible surface groups and the presence of relatively important amount of micropores.

Keywords: A. Polyurethane. C. Infrared spectra. D. Interfaces.

\section{Introduction}

Over the past few years, nanofillers are incorporated to thermoplastic polyurethane (TPU) adhesives in the automotive, footwear and construction industry to improve their rheological, thermal, mechanical and adhesion properties. The performance of TPUnanofiller material is related tightly to their interfacial interactions but detailed studies of such interactions are somewhat rare.

Thermoplastic polyurethane adhesives (TPU) are synthesised by reacting an isocyanate, a polyester, and a chain extender. TPUs show segmented structure composed of soft (non-polar hydrocarbon chain due to the polyester) and hard (polar, produced by reacting the isocyanate and the chain extender) segments, causing phase separation but their properties are dominated by the interactions between the soft segments, i.e. polyester chains. Addition of nanofillers may cause disruption of the phase separation [1, 2]. Precipitated calcium carbonate (PCC), carbon black and fumed silica nanofillers have been used elsewhere for improving the rheological, mechanical 
and adhesion properties of thermoplastic polyurethanes [3-5]. The improved properties of some of these filled polyurethanes were ascribed to the existence of interactions by hydrogen bonding between the nanofiller surface and the polyol moieties. Thus, VegaBaudrit et al. determined that the silanol groups on fumed silica and urethane groups in the polyurethane chains interacted by hydrogen bonding [6]. As a consequence of this, the soft segments were able to move freely and the phase separation increased. On the other hand, Luo et al. added nano-silicas modified with 3methacryloxypropyltrimethoxysilane to polyurethane [7] and they found an increase in mechanical properties of the filled polyurethanes because of creation of covalent bonds between $-\mathrm{C}=\mathrm{O}$ groups on modified silica surface and polymer chains. As a result, the movement of PU chains was limited and the creep resistance of polyurethanes was improved.

Parallel plate rheometry, dynamic mechanical thermal analysis (DMTA) and transmission electron microscopy (TEM) have been used to assess indirectly the nanofiller-polyurethane interactions but they are limited due to the absence of quantitative data at a molecular level. Peng et al investigated the effect of adding modified carbon black on polyurethane foams [8]. They showed an increase in nanofiller-polymer chains interactions by using DMTA experiments.

In previous studies, precipitated calcium carbonate (PCC)-polyurethane interactions were assessed indirectly by parallel plate rheometry and DMTA experiments as well [5]. The addition of PCC increased the elastic modulus of the polyurethane slightly because of the existence of weak PCC-polyurethane interactions. In addition to this, the storage modulus was higher for filled polyurethanes and the glass transition temperature increased from $-23^{\circ} \mathrm{C}$ in the unfilled polyurethane to $-19^{\circ} \mathrm{C}$ in 20 $w t \%$ filled polyurethane. It is probably for the creation of Van der Waals interactions between the polyurethane chains and the surface of PCC particles, which reduce the movement of polyurethane chains.

In this study, the interfacial interactions between the polyurethane chains and the different nanofillers surfaces were studied with a more direct method, flow microcalorimetry (FMC) measurements supported by diffuse reflectance Fourier transform infrared spectroscopy (DRFTIRS). 
FMC enables the measurement of the heats of adsorption and desorption of molecules in solution (and also in the gas phase) on to particulate solid surfaces. Attachment of the cell effluent line to concentration detectors allows determination of the levels of adsorption and desorption. As a result, FMC can be used to investigate and quantify interfacial interactions in composite materials [9-13]. In the existing literature, different fillers including carbon black, silica and organo-clays have been examined using FMC [11, 14-16]. For instance, silica is able to interact with polar adsorbates via hydrogen bonding interactions with surface silanol groups (i.e., isolated, germinal, vicinal varieties) and siloxane bridges [17]. Nevertheless, some grades of carbon black and calcined silicas typically show Van der Waals or hydrophobic interactions with polymers [17]. Occasionally, polymer molecules can also be adsorbed and bond strongly at high energy sites on the carbon black surface [18].

In previously studies, Akoum et al. $[19,20]$ investigated the effect of silica particle size and morphology, and surface energy on poly(dimethylsiloxane) elastomers adsorption. They established that the conformation of polymer chains on the filler surface and how they are connected had an influence on the adsorption phenomena. Additional, the conformation of the macromolecules on silica depended on the silica surface area which was correlated with surface-polymer interactions.

Within the last five years FMC has been applied to studies of bio-diesel fuel manufacture, waste control, organic pollutants and catalysts, within the pharmaceutical, biochemical, chemical and polymer industries [21-25]. However, the use of FMC in studies of interfacial interactions in nanofilled thermoplastic polyurethane adhesive has not yet been reported in the literature. The aim of this study is to use a model compound to simulate the structural units of polyurethane. As the segmented structure of the thermoplastic polyurethanes is mainly dominated by polyester soft segments, in this study dimethyl adipate (DMA) was selected as a probe molecule to simulate the interactions between polyurethane chains and nanofillers of different chemical nature and surface chemistry. 


\section{Experimental}

\subsection{Materials}

Two coated (Socal ${ }^{\circledR} 312$ ) and uncoated (Socal ${ }^{\circledR} 312$ ) precipitated calcium carbonate (PCC, supplied by Solvay Specialités, Salin de Giraud, France), carbon black (CB) (Corax ${ }^{\circledR} \mathrm{N} 134$ supplied by Evonik, Essen, Germany), and fumed silica (Aerosil ${ }^{\circledR} 200$ supplied by Degussa, Hanau, Germany) were used as nanofillers. Some properties of the nanofillers are given in Table 1 [26-28]. All fillers have a mean particle size in the nanometer range, and it is related to their specific surface area. Thus, the fumed silica has the smallest mean particle size and the highest specific surface area, and the PCCs have the biggest mean particle size and the lowest specific surface area.

\section{Table 1 - To be inserted here}

\subsection{Experimental techniques}

2.2.1. Transmission Electron Microscopy (TEM). A Jeol TEM-2010 instrument (Tokyo, Japan) was used to analyse the topography, shape, particle size and degree of agglomeration of the nanofillers; an acceleration voltage of $100 \mathrm{kV}$ was used. The samples were prepared from low concentration suspension of filler particles in ethanol up to obtain a translucent dispersion, and then it was mixed in ultrasonic bath for 4 minutes. A drop of the suspension was put on Lacey grid of $3.05 \mathrm{~mm}$ of diameter, followed by ethanol evaporation at room temperature.

2.2.2. $\mathrm{N}_{2} / 77 \mathrm{~K}$ adsorption-desorption isotherms. The adsorption-desorption isotherms of the nanofillers were obtained in Quantachrome Instrument adsorption system (Quantachrome, Florida, USA). Prior adsorption measurements, the filler was outgassed at $150^{\circ} \mathrm{C}$ for 12 hours at a residual pressure of $10^{-6}$ Torr. From adsorptiondesorption data, specific surface area of nanofillers was obtained by using the B.E.T method and the equation (1) and (2), where $V_{m}$ is adsorbing volume in a monolayer, $C$ is a parameter due to gas-solid interactions, $P$ is equilibrate pressure, $P_{0}$ is saturated 
pressure, $V_{a d s}$ is the $N_{2}$ adsorbing volume, $a_{m}$ is the area of one molecule of $N_{2}$ $\left(16.2 \cdot 10^{-20} \mathrm{~m}^{2}\right), \mathrm{N}_{\mathrm{A}}$ is Avogadro's number, and $\mathrm{V}_{\mathrm{M}}$ is molar volumen of adsorbate (22414 $\left.\mathrm{cm}^{3} \mathrm{~mol}^{-1}\right)$.

$$
\begin{aligned}
& \frac{P}{V_{\operatorname{ads}\left(P_{0}-P\right)}}=\frac{1}{V_{m} C}+\frac{(C-1)}{V_{m} C} \frac{P}{P_{0}} \\
& S_{B E T}=\frac{a_{m} V_{m} N_{A}}{V_{M}}
\end{aligned}
$$

2.2.3. Thermal gravimetric analysis (TGA). The mass loss of the nanofillers as a function of the temperature was measured in TGA Q500 instrument from TA Instruments (New Castle, Delaware, USA). The samples (10-15 mg) were placed in platinum pans and were heated from room temperature to $800^{\circ} \mathrm{C}$ at a heating rate of 10 ${ }^{\circ} \mathrm{C} \mathrm{min}^{-1}$ under nitrogen atmosphere (flow rate: $100 \mathrm{ml} \mathrm{min}^{-1}$ ).

2.2.4. Flow Micro-Calorimetry (FMC). The FMC instrument used was a Microscal $3 \mathrm{~V}$ with polytetrafluoroethylene (PTFE) cell (MICROSCAL Ltd, London, UK). The cell outlet was connected to a Waters 410 differential refractometer (MILLIPORE, Massachusetts, USA). The data outputs were handled by Perkin-Elmer Nelson 970 series interface connected to PC. The volume of the sample chamber was $0.15 \mathrm{~cm}^{3}$ (sufficient filler was used to fill the chamber), and the experiments were carried out at cell temperature of $20 \pm 1{ }^{\circ} \mathrm{C}$. Adsorption experiments were carried out from both heptane and butan-2-one because heptane is the most common solvent used in FMC and butan-2-one is the typical solvent for polyurethane adhesives formulation, at a flow rate of $4.0 \mathrm{ml} \cdot \mathrm{h}^{-1}$. The concentration of the probe solution was $0.3 \mathrm{vol}$. \%. Decahydronaphthalene was used as the non-adsorbing probe.

The butan-2-one and heptane were HPLC grade (Lab-Scan Analytical Sciences, POCH S.A., Gliwice, Poland) and were dried over 3A molecular sieves. The adsorption and desorption of dimethyl adipate (99\%, Aldrich, Dorset, UK) on to the nanofillers in heptane or butan-2-one, was carried out at $20^{\circ} \mathrm{C}$ according to established FMC 
methods $[10,13-17,19,20,24,25]$. After completion of the FMC experiments, the nanofillers were oven dried at $70^{\circ} \mathrm{C}$ for 20 hours, and then examined using diffuse reflectance Fourier transform infrared spectroscopy (DRFTIRS).

\subsubsection{Diffuse reflectance Fourier transform infrared spectroscopy (DRFTIRS). The} species adsorbed on the nanofillers were analysed quantitatively by using a ThermoNicolet Nexus spectrometer (Madison, WI, USA) fitted with standard DTGS detector and Spectra-Tech DRFTIRS cell. Prior to analysis, the samples were diluted to $5 \mathrm{wt} \%$ with finely ground $\mathrm{KBr}$; care was taken to gently fold the sample in to the $\mathrm{KBr}$, in order to avoid damaging the filler particles. DRFTIRS spectra were made up of 160 scans with resolution set to $4 \mathrm{~cm}^{-1}$. Automatic baseline correction and peak integration was carried out using Omnic 5.1 software.

\section{Results and Discussion}

\subsection{Nanofillers characterization}

The shape and size of the nanofiller particles were assessed by TEM (Figure 1). All nanofillers are spherical and have primary particle sizes smaller than $100 \mathrm{~nm}$. The nanoparticles are interconnected by physical interactions and, therefore agglomerates are formed. Precipitated calcium carbonates have the largest particle size and the highest degree of agglomeration, whereas carbon black has smaller particle size and shows some agglomerates. Fumed silica has the smallest particle size but the strongest interconnectivity between particles, likely due to silanol interactions [6].

\section{Figure 1 - To be inserted here}

On the other hand, in this study the nanofillers were selected because of their different surface chemistry. Whereas the hydrophilic fumed silica has surface silanol groups, the calcium carbonate only has carbonate groups, i.e. it does not have hydroxyl groups on the surface $[4,17,28,29]$. Carbon black has several carbon-oxygen and hydroxyl groups on the surface but their nature are different than the silanol groups on 
the fumed silica [30]. The amounts of surface groups on the nanofillers surfaces were obtained from thermal gravimetric analysis (Figures $2 a$ and $2 b$ ).

\section{Figures $2 a$ and $2 b-$ To be inserted here}

TGA thermogram of the uncoated calcium carbonate shows the main decomposition at $704^{\circ} \mathrm{C}$, although coated calcium carbonate shows two main decompositions at 386 and $710^{\circ} \mathrm{C}$ (Figure 2a). The decomposition at $386{ }^{\circ} \mathrm{C}$ corresponds to loss of the stearate coating (3.2 wt\%) which is given from the synthesis process of precipitated calcium carbonate $[31,32]$. The stearate is commonly added to calcium carbonate to avoid particle agglomeration and it is highly probable that precipitated calcium carbonate is coated with stearic acid or ammonium stearate as no other metals can be detected in the chemical analysis of the coated filler by X-ray fluorescence spectroscopy. On the other hand, the decomposition at $704-710^{\circ} \mathrm{C}$ corresponds to $\mathrm{CO}_{2}$ loss due to calcium carbonate decomposition and accounts for 42 wt $\%$.

According to Figure $2 b$, the carbon black shows two main decompositions at 590 ${ }^{\circ} \mathrm{C}$ and $667^{\circ} \mathrm{C}$ that have been ascribed to loss of $\mathrm{CO}_{2}$ and $\mathrm{CO}$, respectively [33]. The decomposition of $\mathrm{CO}_{2}$ at about $600^{\circ} \mathrm{C}$ has been ascribed to carboxylic acid moieties, while the $\mathrm{CO}$ decomposition at about $670^{\circ} \mathrm{C}$ can be ascribed to phenol or carbonyl surface groups $[34,35]$. Therefore, the CB nanofiller contains $3.4 \mathrm{wt} \%$ of volatiles that derive from surface groups, $1.5 \mathrm{wt} \%$ for carboxyl groups and $1.9 \mathrm{wt} \%$ for carbonyl/phenol groups.

On the other hand, the TGA thermogram of the fumed silica in Figure $2 b$ shows two decompositions at 351 and $740^{\circ} \mathrm{C}$ due to the surface silanol groups of different nature (isolated silanols, and vicinal silanols and germinal silanol, respectively) [17, 29, 36]. Thus, the fumed silica contains $3.8 \mathrm{wt} \%$ of surface silanol groups, $1.5 \mathrm{wt} \%$ for isolated silanols and $1.9 \mathrm{wt} \%$ for vicinal and germinal silanols.

\subsection{Adsorption/desorption of dimethyl adipate from heptane on to the nanofillers}


The adsorption/desorption of dimethyl adipate (i.e. model probe of polyester in thermoplastic polyurethane) on the different nanofillers were investigated by using two different solvents, one non-polar (heptane) and one polar, butan-2-one. Heptane is a standard solvent for FMC experiments and butan-2-one is commonly used as solvent of thermoplastic polyurethane adhesive.

Figure 3 shows the heats of adsorption and desorption of dimethyl adipate (DMA) from heptane on to coated and uncoated precipitated calcium carbonates (PCCs), carbon black (CB) and fumed silica. The untreated PCC shows more energetic adsorption relative to the stearate treated sample, in agreement with other studies [3740] that showed that the stearate coating of calcium carbonate blocked adsorption sites, resulting in relatively low DMA adsorption (Figure 3). The adsorption of DMA on to fumed silica is more energetic than adsorption on to the other three substrates. Fumed silica contains $3.8 \mathrm{wt} \%$ silanol groups on the surface which are able to interact by hydrogen bonding with the $-\mathrm{C}=\mathrm{O}$ polar groups of DMA [17]. On the other hand, the heat of adsorption of DMA on carbon black is extremely low due to the relatively low concentration of surface functional groups in relation to the surface area available. TGA analysis indicated that the $\mathrm{CB}$ contains $1.5 \mathrm{wt} \% \mathrm{COOH}$ groups and $1.9 \mathrm{wt} \% \mathrm{C}=\mathrm{O}$ groups, and it may be assumed that the majority of these groups are on the CB surface but they may not all be accessible to the DMA. It has been shown that carbon black surface functional groups generally interact rather weakly in solution adsorption experiments [41]. Moreover, the presence of adsorbed water (0.9 wt\%), part of which may remain on the surface even after conditioning in the FMC overnight with dry heptane, can in some cases reduce the adsorption activity of CB due to blockage of adsorption sites by water molecules [41].

\section{Figure 3 - To be inserted here}

The heat of desorption of DMA from fumed silica in heptane is lower than the heat of adsorption, indicating that some DMA is retained on the fumed silica surface. However, the heats of desorption of DMA from PCC and CB nanofillers in heptane (Figure 3) are higher than their corresponding heats of adsorption, particularly for 
coated PCC. This can be ascribed to the partial removal of the stearate coating on the calcium carbonate surface that can be detached by heptane. On the other hand, as the same happens for the uncoated calcium carbonate but the differences between the heats of adsorption and desorption are smaller, it can be suggested that additional to dimethyl adipate adsorption some capillary condensation between the calcium carbonate particles can be produced (the particle size of the two calcium carbonates is much larger than for the other fillers favouring the existence of larger voids between them) contributing to higher heat of desorption than expected. Furthermore, for carbon black, the higher heat of desorption can be also associated with water which is being desorbed together with the DMA.

\section{Figure 4 - To be inserted here}

Substrate subtracted DRFTIRS spectra of dried uncoated and coated PCC, and fumed silica after adsorption/desorption of DMA from heptane are given in Figure 4. Dried CB cannot be characterized by DRFTIRS because a noisy spectrum was obtained. The DRFTIRS spectrum of DMA (Figure 4) shows a very intense absorbance band at $1720 \mathrm{~cm}^{-1}$ which correspond to the $\mathrm{C}=\mathrm{O}$ stretching of the ester group. For this reason, this absorption band was used to determine the level of DMA retention on the substrates. The DRFTIRS spectrum of fumed silica clearly shows retention of DMA on the surface, in agreement with the reduced heat of desorption (Figure 3). In fact, the DRFTIRS spectrum shows a strong ester carbonyl band that has been broadened significantly indicating varying strengths of interaction between DMA and surface silanol groups. Careful inspection of the peak indicates two main contributions, the most dominant results in a peak which is blue-shifted relative to DMA in its liquid state, whilst the less significant component is red-shifted. Previous studies examining adsorption of molecules featuring ester groups on to silica have revealed only red-shifting of the carbonyl band which has been ascribed to interaction with isolated silanol groups [17]. It has to be appreciated, however that the overall level of silanol groups in the fumed silica (as measured by TGA and as according to DRFTIRS spectrum) is rather lower than those in the gel silicas previously examined. Therefore, interaction between the siloxane 
linkages and the ester groups of DMA may in fact be the dominant mode of adsorption. Interaction of the lone pair of the -C-O- group of the ester with a siloxane linkage may result in an increase in carbonyl stretching frequency. Further work will be required to verify this proposition.

The substrate subtracted DRFTIRS spectrum of uncoated PCC after adsorption/desorption of DMA shows a perturbed carbonyl band at $1712 \mathrm{~cm}^{-1}$ as a consequence of DMA-uncoated PCC interactions. However, the substrate subtracted DRFTIRS spectrum of coated PCC after adsorption/desorption of DMA shows several weak absorption bands and an unperturbed carbonyl band at $1725 \mathrm{~cm}^{-1}$. The absence of shifting of this band may be significant in that a large fraction of the carbonyls are not interacting with the coated PCC surface, but instead resting on, and within, the stearate coating.

Figure 5 shows the variation of the heats of adsorption of DMA from heptane on to the substrates as a function of specific surface area. In non-porous materials, by increasing the specific surface area, higher level of adsorption can be expected, this general trend can be observed in Figure 5. However, the heat of adsorption of carbon black is lower than expected according to its surface area. Figure 6 shows the nitrogen adsorption isotherm at $77 \mathrm{~K}$ of the carbon black. The adsorption isotherm corresponds to mesoporous solids (pore sizes between 2 and $50 \mathrm{~nm}$ ) and an important adsorption at high relative pressure is obtained due to the adsorption on the external surface.

However, at very low relative pressure (below 0.01) a noticeable adsorption due to the micropores (pores below $2 \mathrm{~nm}$ in diameter) is noticed. As the size of DMA is larger than $2 \mathrm{~nm}$, DMA can only be adsorbed on the mesoporores and the external surface area of the carbon black, both contributing to a minor amount of the measured specific surface area. Therefore, the heat of adsorption of DMA on carbon black should be lower than expected according its specific surface area.

Figures 5 and 6 - To be inserted here

\subsection{Adsorption/desorption of butan-2-one from heptane on to the nanofillers}


Because butan-2-one is a common solvent for thermoplastic polyurethane adhesives, the heats of adsorption and desorption of butan-2-one from heptane on to precipitated calcium carbonate and fumed silica nanofillers were measured. Figure 7 shows that the heat of adsorption of butan-2-one on fumed silica is higher than for precipitated calcium carbonates, a trend similar to that obtained in the adsorption experiments of DMA. The silanol groups on the fumed silica surface interact with the $\mathrm{C}=\mathrm{O}$ group of butan-2-one by hydrogen bonding, whilst precipitated calcium carbonate PCC interacts with the $-\mathrm{C}=\mathrm{O}$ group of butan-2-one by Van der Waals forces only $[17,38]$.

\section{Figure 7 - To be inserted here}

On the other hand, according to Figure 7 the heats of desorption of butan-2-one from heptane are slightly higher than the corresponding heats of adsorption, but the differences between the heats of adsorption and desorption are lower than in the DMA adsorption experiments (Figure 3).

Figure 8 shows the substrate subtracted DRFTIRS spectra of dried nanofillers after adsorption and desorption of butan-2-one from heptane. The DRFTIRS spectrum of butan-2-one shows two absorbance bands at 2975 and $2950 \mathrm{~cm}^{-1}$ due to the $-\mathrm{CH}_{2}$ and $-\mathrm{CH}_{3}$ stretching, a high absorbance band of the $-\mathrm{C}=\mathrm{O}$ group stretching at $1720 \mathrm{~cm}^{-}$ ${ }^{1}$ and an absorbance band at $1360 \mathrm{~cm}^{-1}$ due to $-\mathrm{CH}_{3}$ group bending. Comparing these absorbance bands with the substrate subtracted DRFTIRS spectra of precipitated calcium carbonates and fumed silica, none of them show retention of butan-2-one on the fumed silica surface, although a slightly absorbance band at $1750 \mathrm{~cm}^{-1}$ in the coated precipitated calcium carbonate spectrum is seen. As a result, the butan-2-one is more easily desorbed than DMA.

\section{Figure 8 - To be inserted here}

On the other hand, the specific surface area of the nanofillers has an influence on the heats of adsorption/desorption of butan-2-one from heptane (Table 2). Higher heat 
of adsorption/desorption of butan-2-one on the fillers is produced by increasing their specific surface area, as both fillers are non-porous and only have external surface area.

\section{Table 2 - To be inserted here}

\subsection{Adsorption/desorption of dimethyl adipate from butan-2-one on to the nanofillers}

Dimethyl adipate was used as a model probe from butan-2-one for measuring the heats of adsorption/desorption of the different nanofillers. Figure 9 shows the heats of adsorption and desorption of DMA from butan-2-one on to precipitated calcium carbonates and fumed silica.

\section{Figure 9 - To be inserted here}

The fumed silica shows again more energetic DMA adsorption relative to precipitated calcium carbonates (Figure 9). Furthermore, the heats of adsorption of DMA from butan-2-one are considerably lower that from heptane due to the stronger interactions between the polar solvent butan-2-one and the nanofillers surface. It is possible that the highest energy adsorption sites on the nanofillers may be blocked by the butan-2-one solvent molecules. In fact, the heats of desorption of DMA from butan2-one in both nanofillers are very low, likely due to the retention of the solvent on the more active sites of the nanofiller surface.

Substrate subtracted DRFTIRS spectra of precipitated calcium carbonates and fumed silica dried nanofillers after adsorption and desorption of DMA from butan-2-one are given in Figure 10. The lower levels of adsorption from butan-2-one are immediately apparent as the ester carbonyl of samples where DMA was adsorbed from butan-2-one is rather weak relative equivalent samples where DMA was adsorbed from heptane. DRFTIRS spectra show retention of DMA on the fumed silica surface and to a lesser extent on precipitated calcium carbonates surface. In both cases, the ester carbonyl band shifted to higher energy indicating at $1725 \mathrm{~cm}^{-1}$ and $1740 \mathrm{~cm}^{-1}$ which correspond 
to fumed silica and coated precipitated calcium carbonate, respectively, and a lower energy at $1712 \mathrm{~cm}^{-1}$ to uncoated precipitated calcium carbonate.

\section{Figure 10 - To be inserted here}

Table 3 included the variation of the heats of adsorption of DMA in butan-2-one from heptane on to the nanofillers as a function of the nanofiller specific surface area. The heat of adsorption increases by increasing the specific surface area.

\section{Table 3 - To be inserted here}

\section{Conclusions}

Dimethyl adipate (DMA) has been used as a model compound to simulate the polyester based polyol component of a thermoplastic polyurethane. The interaction of the latter with a range of nanofillers of diverse surface properties was studied by FMC, supported by DRFTIRS analysis of samples isolated from the FMC cell. Carbonyl groups of DMA interacted strongly with silanol groups on the fumed silica surface via hydrogen bond formation. The interaction of dimethyl adipate and the untreated surface of precipitated calcium carbonate was via weaker Van der Waals forces. Dimethyl adipate strongly adsorbed onto fumed silica and uncoated precipitated calcium carbonate, and slightly onto coated precipitated calcium carbonate and carbon black. Stearate treatment of precipitated calcium carbonate greatly reduced the strength of interaction with the DMA due to blockage of the surface adsorption sites. In general, higher surface area loading a high level of adsorption because of the nanofiller had more adsorption sites. Carbon black is an exception likely due to the less accessible surface groups and the presence of relatively important amount of micropores.

On the other hand, butan-2-one (a common solvent for thermoplastic polyurethane adhesives) competed with DMA for adsorption on nanofillers surface, mainly fumed silica. In fact, the trend in adsorption/desorption of DMA and butan-2-one were similar in FMC experiments, but the butan-2-one was more easily desorbed from the nanofillers surfaces. Finally, the heats of DMA adsorption from butan-2-one were considerably 
lower than from heptane owing to the stronger interactions between the solvent and the nanofillers by blocking the energy adsorption sites.

Acknowledgments. Authors would like to thank Solvay Specialités for supply of the precipitated calcium carbonate samples and Evonik for supply of carbon black and fumed silica used in this study. J. Donate-Robles would like to thank the office of the Vice President for Research at the University of Alicante for funding of her PhD study and funding of her three months visit to the Centre for Materials Science Research at the Manchester Metropolitan University (MMU). Much of the work presented in this paper was conducted during this visit to MMU.

\section{References}

[1] Frisch KC Jr. Adhesion Science and Engineering: Surfaces, Chemistry and Applications, A.V. Pocius, M. Chaudhury (Ed). Elsevier, Amsterdam: Holland; 2003, p.760.

[2] Król P. Synthesis methods, chemical structures and phase structures of linear polyurethanes. Properties and applications of linear polyurethanes in polyurethane elastomers, copolymers and ionomers. Prog Mater Sci 2007; 52(6): 915-1015.

[3] Wypych G. Handbook of fillers, ChemTec Publishing \& Plastics Design Library, Canada: Toronto; 2000.

[4] Vega-Baudrit J, Navarro-Bañón V, Vázquez P, Martín-Martínez JM. Addition of nanosilicas with different silanol content to thermoplastic polyurethane adhesives. Int $\mathrm{J}$ Adhes Adhes 2006; 26(5): 378-387.

[5] Donate-Robles J, Martín-Martínez JM. Addition of precipitated calcium carbonate filler to thermoplastic polyurethane adhesives. Int J Adhes Adhes 2011; 31(8): 795-804. [6] Vega Baudrit J, Sibaja-Ballestero M, Vázquez P, Torregrosa-Maciá R, Martín Martínez JM. Properties of thermoplastic polyurethane adhesives containing nanosilicas with different specific surface area and silanol content. Int J Adhes Adhes 2007; 27(6): 469-479. 
[7] Luo Z, Hong RY, Xie HD, Feng WG. One-step synthesis of functional silica nanoparticles for reinforcement of polyurethane coatings. Powder Technol 2012; 218: 23-30.

[8] Peng M, Zhou M, Jin Z, Kong W, Xu Z, Vadillo D. Effect of surface modifications of carbon black (CB) on the properties of CB/polyurethane foams. J Mater Sci 2010; 45(4): 1065-1073.

[9] Groszek AJ. Flow adsorption microcalorimetry. Thermochim Acta 1998; 312(1-2): 133-143.

[10] Liauw CM, Rothon RN, Hurst SJ, Lees GC. The use of flow micro-calorimetry and FTIR techniques for characterizing filler/organic acid interactions. Compos Interface 1998; 5(6): 503-514.

[11] Liauw CM, Childs A, Allen NS, Edge M, Franklin KR, Collopy DG. Effect of interactions between stabilisers and silica used for anti-blocking applications on UV and thermal stability of polyolefin film 1. Adsorption studies. Polym Degrad Stab 1999; 63(3): 391-397.

[12] Rodríguez de Rivera M, Socorro F. Flow microcalorimetry and thermokinetics of liquid mixtures. J Therm Anal Calorim 2007; 87(2): 591-594.

[13] Groszek AJ. Hydrogen and noble gas interactions with iron nano-flakes. Appl Surf Sci 2007; 253(13): 5882-5887.

[14] Peña JM, Allen NS, Liauw CM, Edge M, Valange B, Santamaria F. Factors affecting the adsorption of stabilizers on to carbon black (flow micro-calorimetry studies) Part III Surface activity study using acid/base model probes. J Mater Sci 2001; 36(18): 4443-4457.

[15] Akoum RA, Haidar B, Vidal A. Effect of silica particle size on polymer adsorption. Morphological, energetic and conformational relationship, University of Alicante, Proceedings Eurofillers 2003, Alicante, Spain. 8-11 September, 2003. pp. 289-292. [16] Liauw CM, Lees GC, McMahon AW, Rothon RN, Rego CA, McLaughlin PJ. Surface activity studies on carbon-silica dual phase fillers using flow microcalorimetry and multiple probe temperature programmed inverse gas chromatography. Compos Interface 2005; 12(3-4): 201-220. 
[17] Diaz L, Liauw CM, Edge M, Allen NS, McMahon A, Rhodes N. Investigation of factors affecting the adsorption of functional molecules onto gel silicas. 1. Flow microcalorimetry and infrared spectroscopy. J Colloid Interf Sci 2005; 287(2): 379-387. [18] Peña JM, Allen NS, Edge M, Liauw CM, Santamaria F. Factors affecting the adsorption of stabilizers on to carbon black (flow microcalorimetry and FTIR studies) Part I Primary phenolic antioxidants. J Mater Sci 2001; 36(12): 2885-2898.

[19] Akoum RA, Haidar B, Vidal A. Effect of silica particle size on polymer adsorption. Morphological, energetic and conformational relationships. Macromol Symp 2005; 221 : 271-280.

[20] Akoum RA, Vaulot C, Schwartz D, Hirn MP, Haidar B. How silanization of silica particles affects the adsorption of PDMS chains on its surface. J Polym Sci Pol Phys 2010; 48(22): 2371-2378.

[21] Lantenois S, Prélot B, Douillard JM, Szczdrowski K, Charbonnel MC. Flow microcalorimetry: Experimental development and application to adsorption of heavy metal cations on silica. Appl Surf Sci 2007; 253(13): 5807-5813.

[22] Dragoi B, Rakic V, Dumitriu E, Auroux A. Adsorption of organic pollutants over microporous solids investigated by microcalorimetry techniques. J Therm Anal Calorim 2010; 99(3): 733-740.

[23] Katiyar A, Thiel SW, Guliants VV, Pinto NG. Investigation of the mechanism of protein adsorption on ordered mesoporous silica using flow microcalorimetry. J Chromatogr A 2010; 1217(10): 1583-1588.

[24] Kato R, Liauw CM, Allen NS, Irure A, Wilkinson AN, Stanford JL, Fithriyah NH. Interfacial interactions in polymer-layered silicate nanocomposites. Langmuir 2008; 24(5): 1943-1951.

[25] Wilkinson AN, Fithriyah NH, Stanford JL, Suckley D, Kato R, Allen NS, Liauw CM. Structure development and interfacial interactions in flexible polyurethane foamlayered silicate nanocomposites. Compos Interfaces 2010; 17(5-7): 423-436. [26] Solvay Advanced Functional Minerals, Socal ${ }^{\circledR} 312$ and Socal ${ }^{\circledR} 31$ data sheet, SpecialChem S.A., http://www.specialchem4adhesives.com/ (accessed January 2011). 
[27] Evonik Industries, Corax N134 data sheet, Evonik Degussa GmbH, Advanced Fillers and Pigments, http://corporate.evonik.com/en/Pages/default.aspx (accessed January 2009).

[28] Technical Bulletin Aerosil, Aerosil for Unsaturated Polyester Resins and Vinyl Ester Resins n54, Degussa AG, Dusseldorf, Germany, Ch 11.p.28.

[29] Wacker silicones, HDK-Pyrogenic silica, Wacker Chemie AG, http://www.wacker.com/cms/media/publications/downloads/6174_EN.pdf (accessed July 2012).

[30] Wang MJ, Gray CA, Reznek SR, Mahmud K, Kutsovsky Y. Encyclopedia of Polymer Science and Technology, Vol. 9, John Wiley \& Sons, 2004, 52.

[31] Moreira APD, Souza BS, Teixeira AMRF. Monitoring of calcium stearate formation by thermogravimetry. J Therm Anal Calorim 2009; 97: 647-652.

[32] Tran HV, Tran LD, Vu HD, Thai H. Facile surface modification of nanoprecipitated calcium carbonate by adsorption of sodium stearate in aqueous solution. Colloid Surface A 2010; 366(1-3): 95-103.

[33] Jakab E, Omastová M. Thermal decomposition of polyolefin/carbon black composites. J Anal Appl Pyrolisis 2005; 74(1-2): 204-214.

[34] Binak S, Szymanski G, Siedlewski J, Swiatkowski A. The characterization of activated carbons with oxygen and nitrogen surface groups. Carbon 1997; 35(12): 1799-1810.

[35] Figueiredo JL, Pereira MFR, Freitas MMA, Órfao JJM. Modification of the surface chemistry of activated carbons. Carbon 1999; 37(9): 1379-1389.

[36] Morrow AM, Allen NS, Edge M, Aldcroft D, Jones H. A kinetic investigation into the effect of stabilizers on the photo-oxidation of water based silica acrylic-based coatings. Polym Degr Stab 2000; 69(2): 143-156.

[37] Ahsan T. The surface properties of pure and modified precipitated calcium carbonate by adsorption of nitrogen and water vapor. Colloid Surface 1992; 64(2): 167176.

[38] Song MG, Kim JY. Effect of sodium stearate and calcium ion on dispersion properties of precipitated calcium carbonate suspensions. Colloid Surface A 2003; 229(1-3): 75-83. 
[39] Rungruang P, Grady BP, Supaphol P. Surface-modified calcium carbonate particles by admiceller polymerization to be used as filler for isotactic polypropylene. Colloid Surface A 2006; 275(1-3): 114-125.

[40] Shi X, Rosa R, Lazzeri A. On the coating of precipitated calcium carbonate with stearic acid in aqueous medium. Langmuir 2010; 26(11): 8474-8482.

[41] Peña JM, Allen NS, Edge M, Liauw CM, Valange B. Interactions between carbon black and stabilizers in LDPE thermal oxidation. Polym Degrad Stabil 2001; 72(1): 163174.

Table 1. Some properties of the nanofillers.

\begin{tabular}{lcc}
\hline \multicolumn{1}{c}{ Nanofiller } & $\begin{array}{c}\text { Specific surface area } \\
{\left[\mathbf{m}^{\mathbf{2}} \mathbf{~ g}^{-1}\right]}\end{array}$ & $\begin{array}{c}\text { Mean particle size } \\
\text { [nm] }\end{array}$ \\
\hline $\begin{array}{l}\text { Coated precipitated calcium } \\
\text { carbonate }\end{array}$ & 19 & 70 \\
Uncoated precipitated & 20 & 70 \\
calcium carbonate & 159 & $<20$ \\
Carbon black & 225 & 12 \\
Fumed silica & & \\
& \\
& a) Data taken from the technical data sheets $[26-28]$.
\end{tabular}

Table 2. Heats of adsorption/desorption of butan-2-one from heptane on to the nanofillers.

\begin{tabular}{lcc}
\hline Nanofiller & $\begin{array}{c}\text { Heat of adsorption } \\
{\left[\mathrm{mJ}^{-1} \mathbf{g}^{-1}\right]}\end{array}$ & $\begin{array}{c}\text { Heat of desorption } \\
{\left[\mathrm{mJ}^{-1} \mathbf{g}^{-1}\right]}\end{array}$ \\
\hline $\begin{array}{l}\text { Coated } \\
\text { precipitated } \\
\text { calcium } \\
\text { carbonate }\end{array}$ & 510 & 920 \\
$\begin{array}{l}\text { Uncoated } \\
\text { precipitated } \\
\text { calcium }\end{array}$ & 1580 & \\
carbonate & & 1610 \\
$\begin{array}{l}\text { Fumed } \\
\text { silica }\end{array}$ & 27600 & \\
\end{tabular}


Table 3. Heats of adsorption/desorption of dimethyl adipate from butan-2-one on to the nanofillers.

\begin{tabular}{lcc}
\hline Nanofiller & $\begin{array}{c}\text { Heat of adsorption } \\
{\left[\mathbf{m J} / \mathbf{~ g}^{-1}\right]}\end{array}$ & $\begin{array}{c}\text { Heat of desorption } \\
{\left[\mathbf{m J} / \mathbf{~ g}^{-1}\right]}\end{array}$ \\
\hline $\begin{array}{l}\text { Coated } \\
\text { precipitated } \\
\text { calcium } \\
\text { carbonate }\end{array}$ & 180 & 25 \\
$\begin{array}{l}\text { Uncoated } \\
\text { precipitated } \\
\text { calcium } \\
\text { carbonate }\end{array}$ & 530 & \\
$\begin{array}{l}\text { Fumed } \\
\text { silica }\end{array}$ & & 90 \\
\end{tabular}

\section{FIGURE CAPTIONS}

Figure 1. TEM micrographs of coated precipitated calcium carbonate (coated PCC), uncoated precipitated calcium carbonate (uncoated PCC), carbon black (CB) and fumed silica.

Figure 2a. TGA thermograms of the nanofillers.

Figure $\mathbf{2 b}$. TGA thermograms of the nanofillers. $100-95 \mathrm{wt} \%$ region.

Figure 3. Heats of adsorption/desorption of dimethyl adipate from heptane on to the nanofillers.

Figure 4. Substrate subtracted DRFTIRS spectra of precipitated calcium carbonates and fumed silica samples isolated from the FMC cell after adsorption/desorption experiments. The dimethyl adipate spectrum has been reduced to fit.

Figure 5. Heats of adsorption of dimethyl adipate from heptane on to the nanofillers as a function of the nanofiller specific surface area.

Figure 6. (a) $\mathrm{N}_{2} / 77 \mathrm{~K}$ adsorption-desorption isotherm of carbon black filler; (b) 0-0.9 relative pressure region.

Figure 7. Heats of adsorption/desorption of butan-2-one from heptane on to the nanofillers.

Figure 8. Substrate subtracted DRFTIRS spectra of the nanofillers isolated from the FMC cell after butan-2-one adsorption/desorption experiments. 
Figure 9. Heats of adsorption/desorption of dimethyl adipate from butan-2-one on to the nanofillers: coated and uncoated precipitated calcium carbonate (PCC), fumed silica. Figure 10. Substrate subtracted DRFTIRS spectra of the nanofillers isolated from the FMC cell after adsorption/desorption experiments. The dimethyl adipate spectrum has been reduced to fit. 

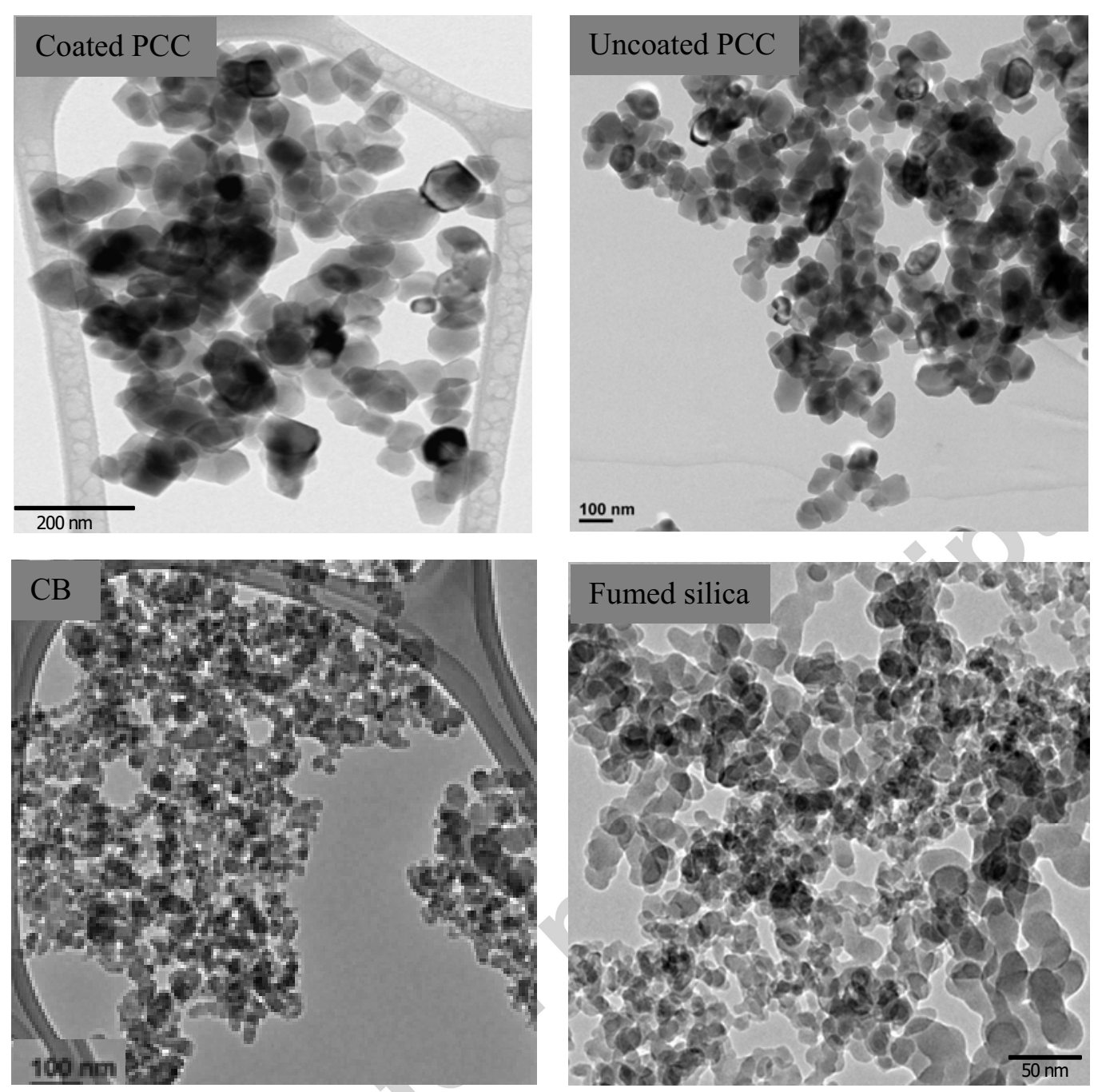

Figure 1 


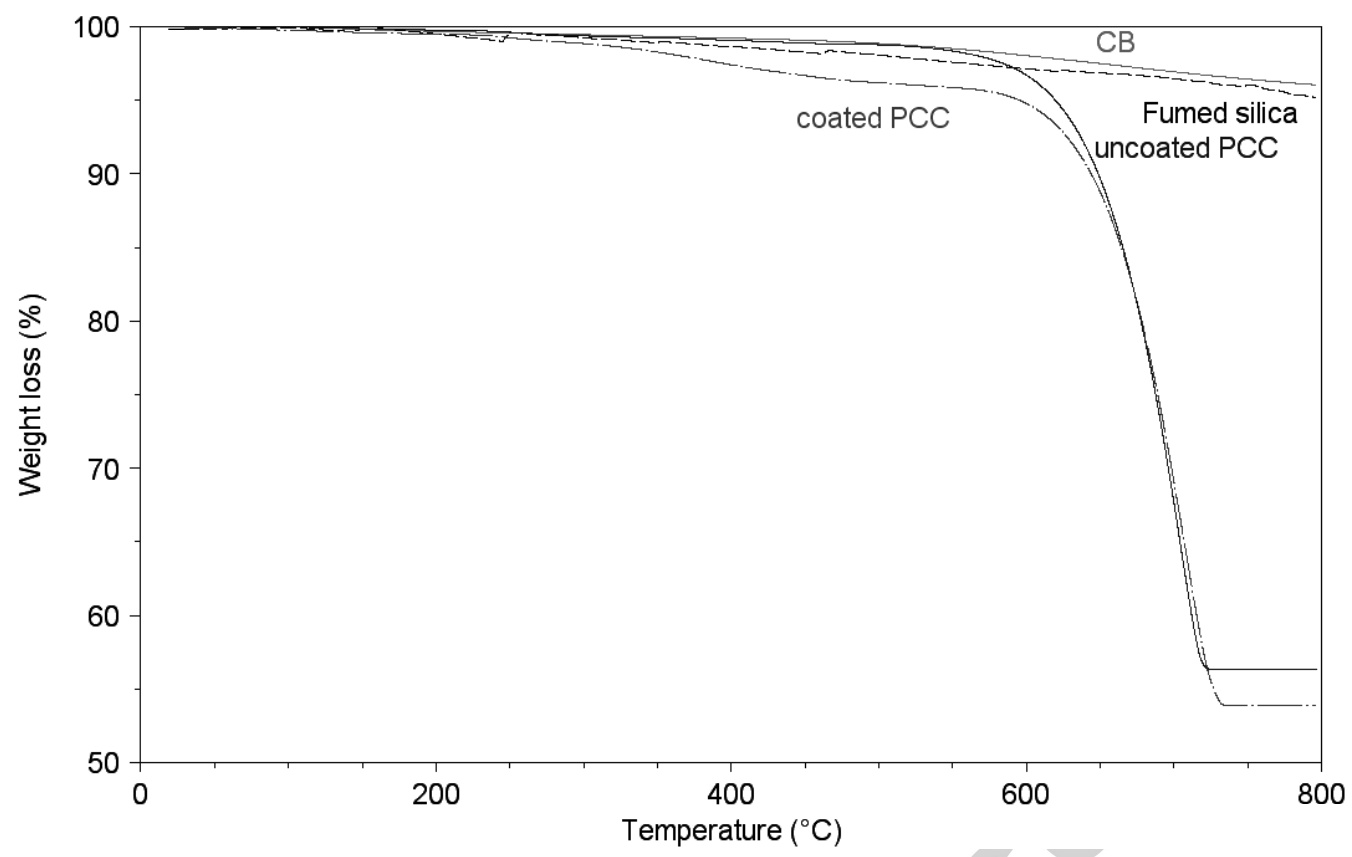

Figure 2a

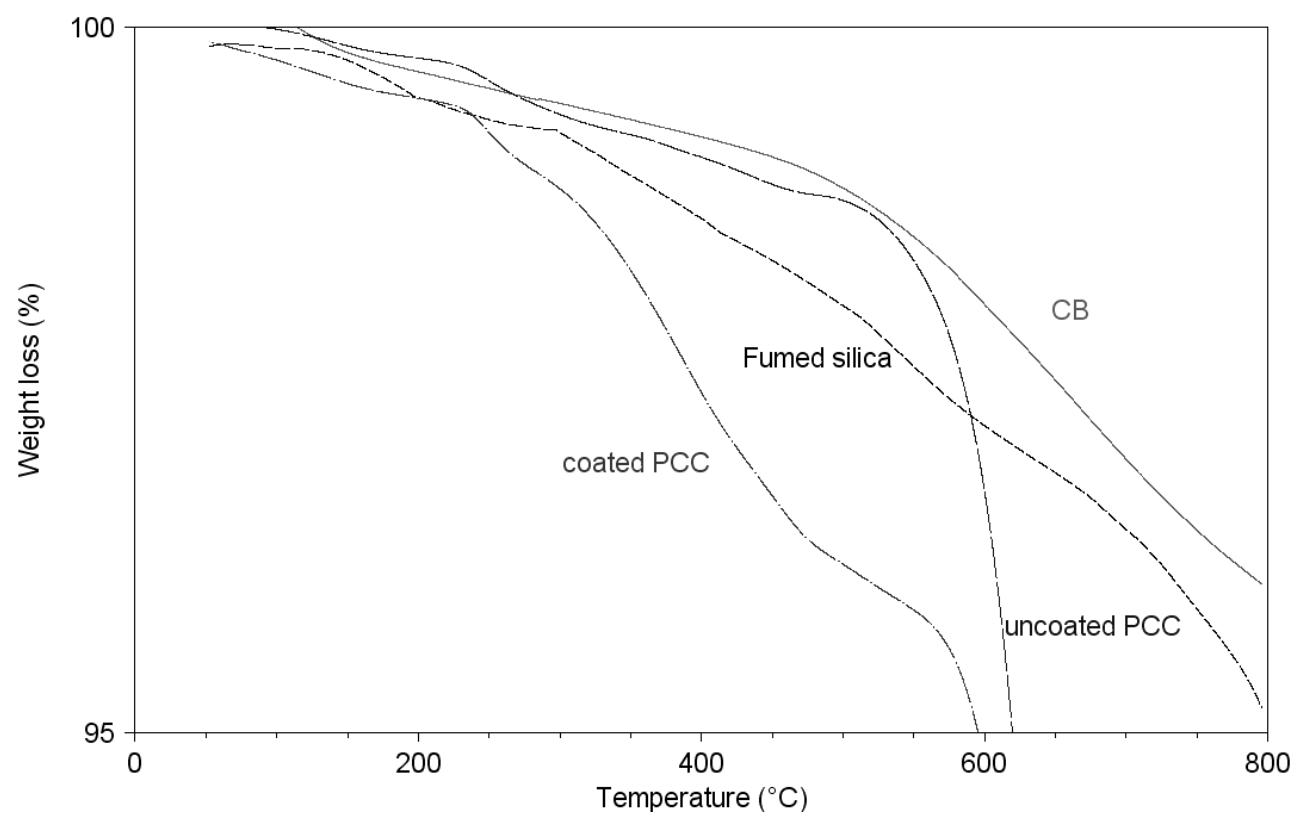

Figure 2b 


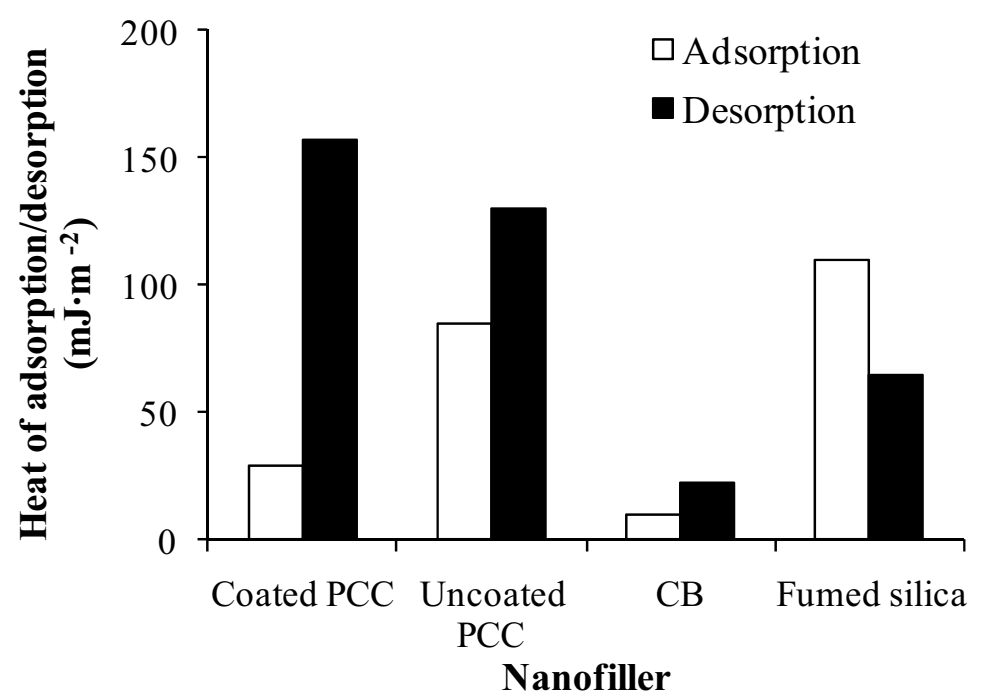

Figure 3

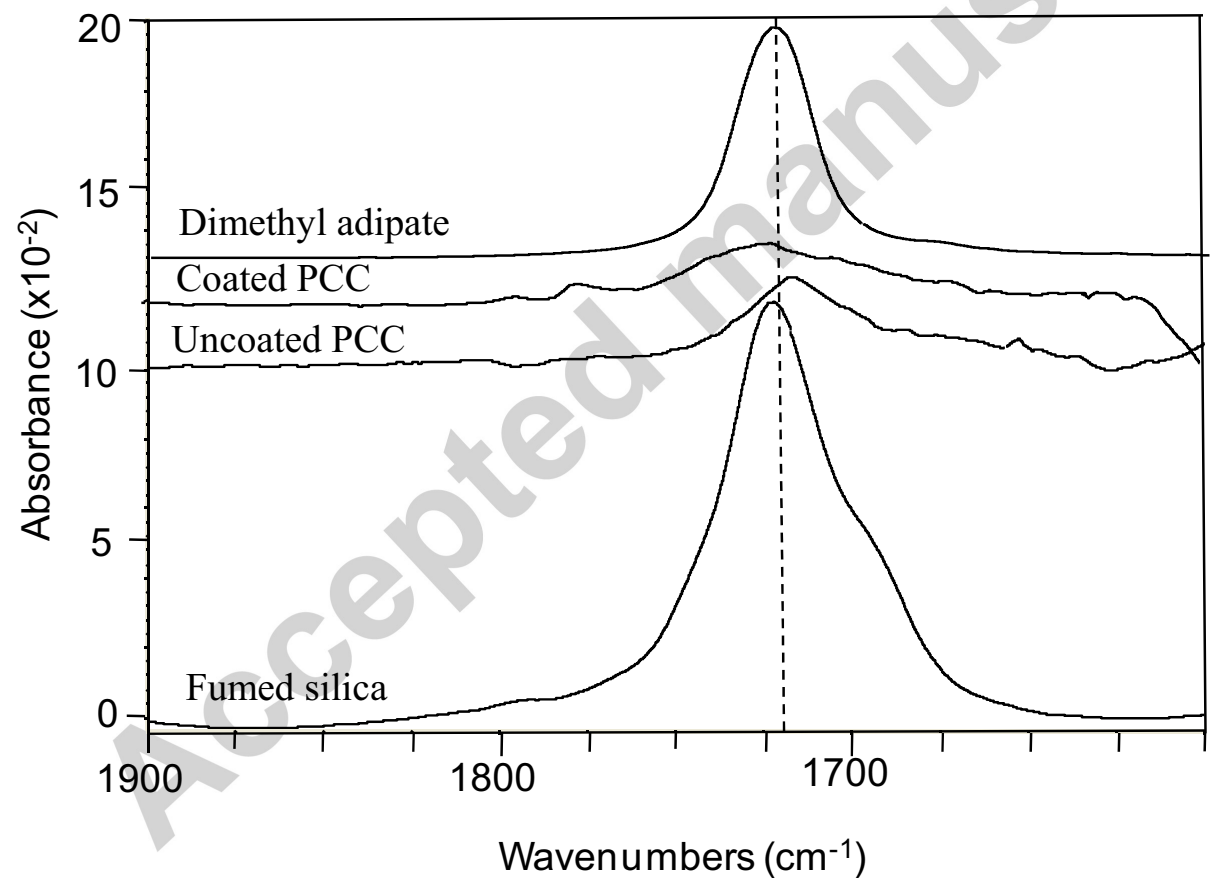

Figure 4 


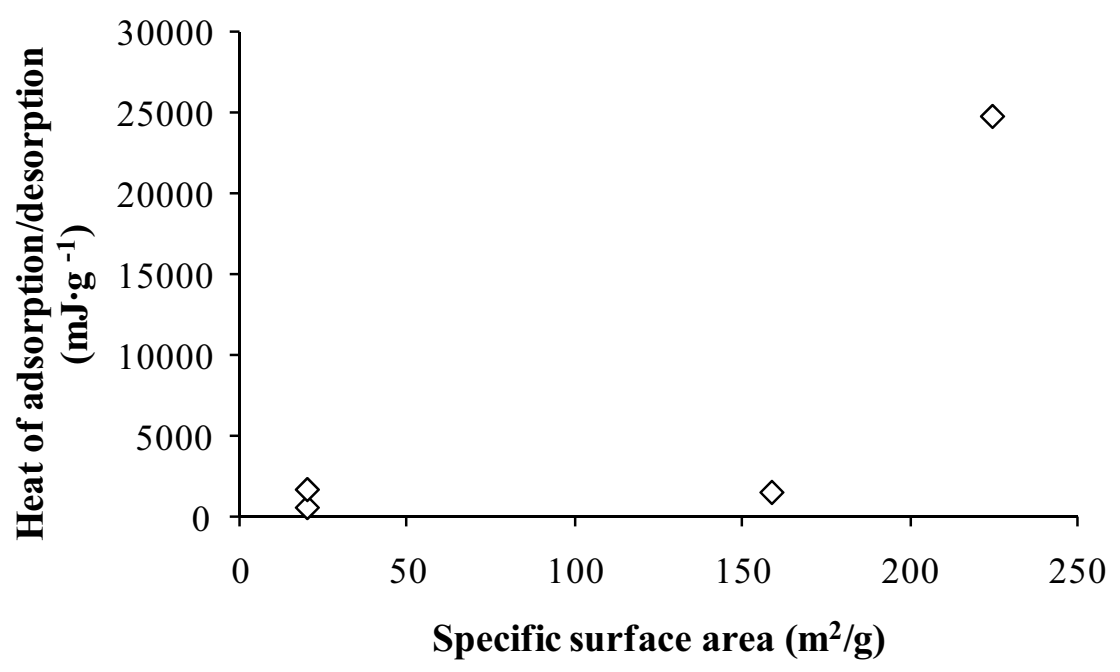

Figure 5

(a)

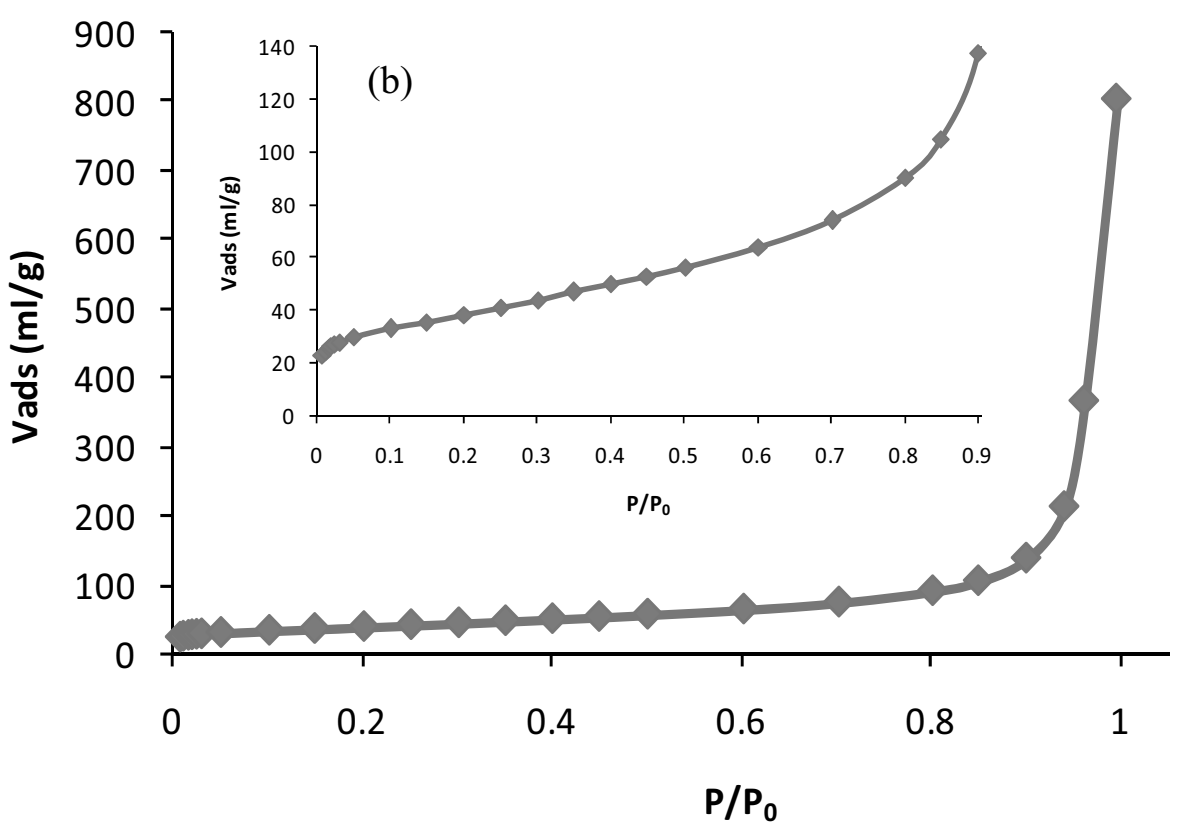

Figure 6 


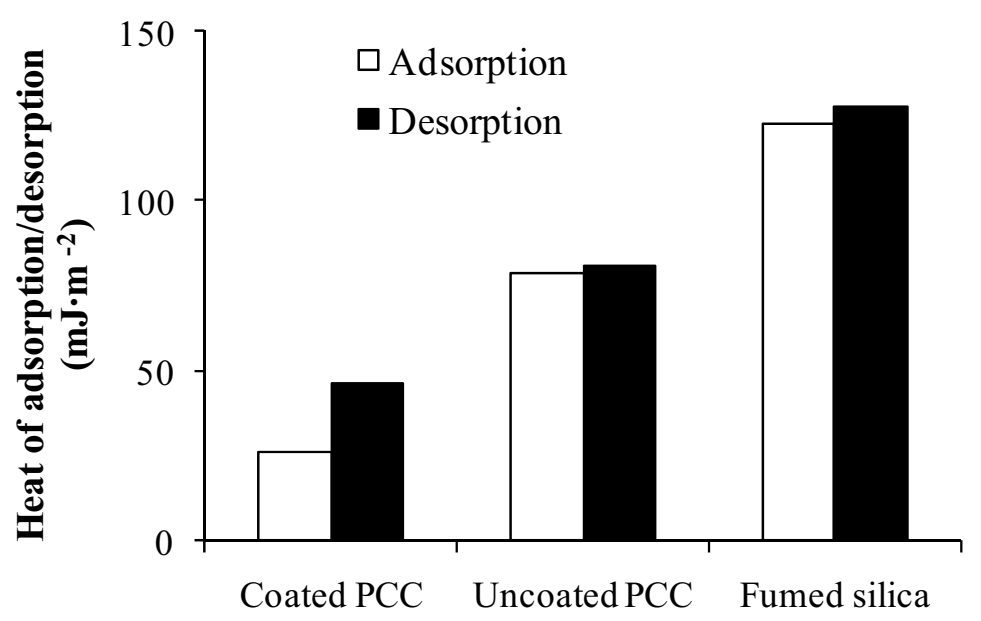

Nanofiller

Figure 7

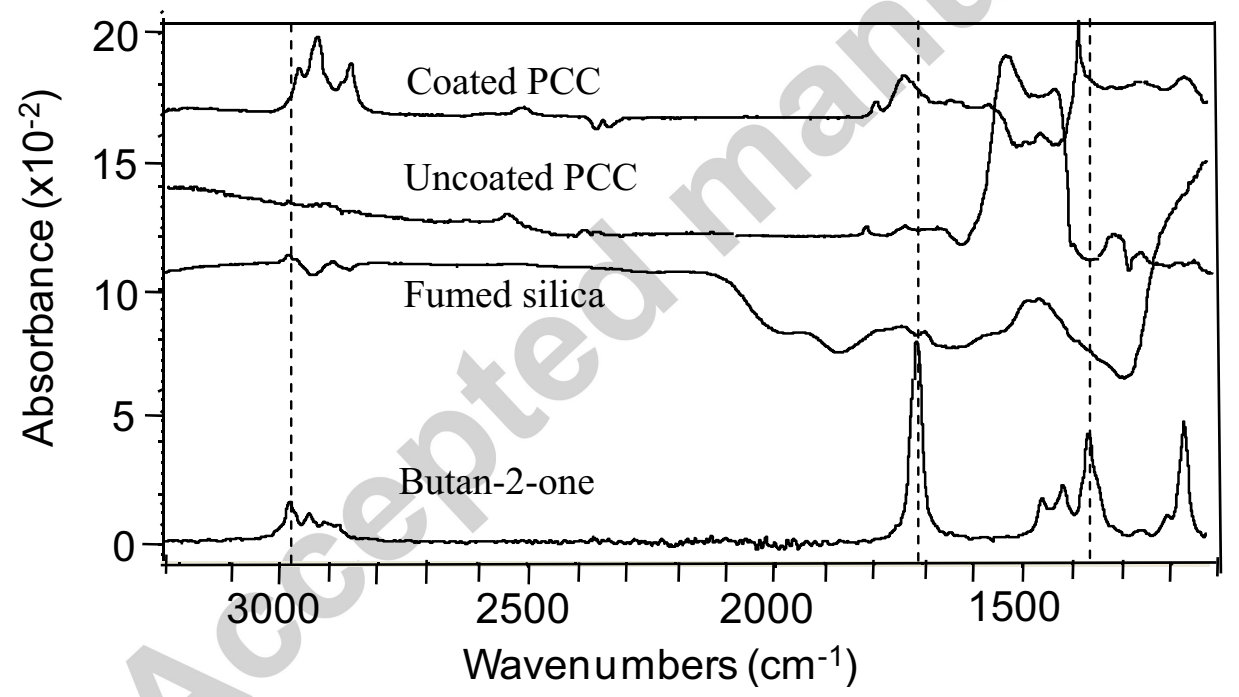

Figure 8 


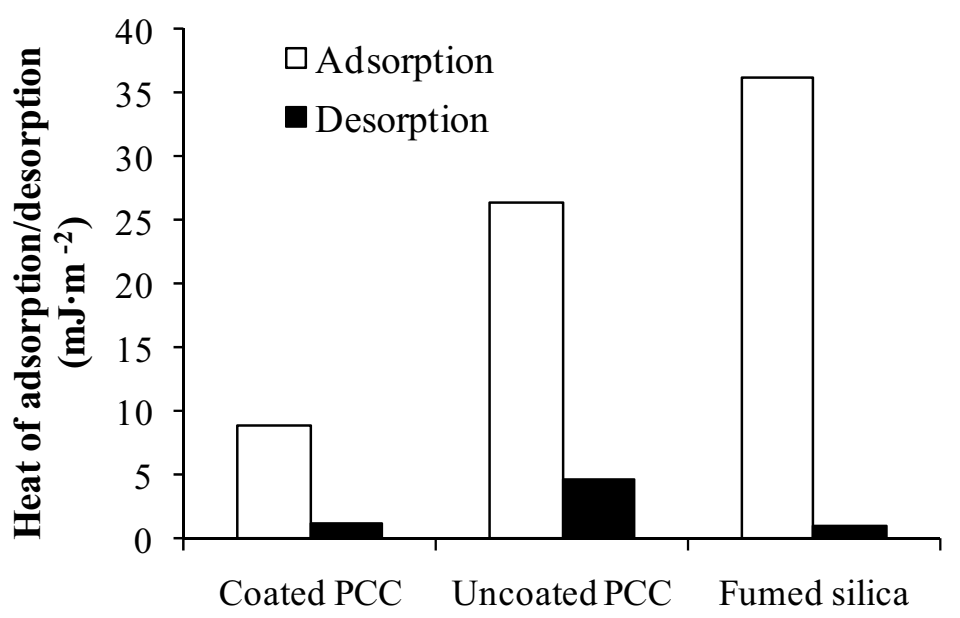

Nanofiller

\section{Figure 9}

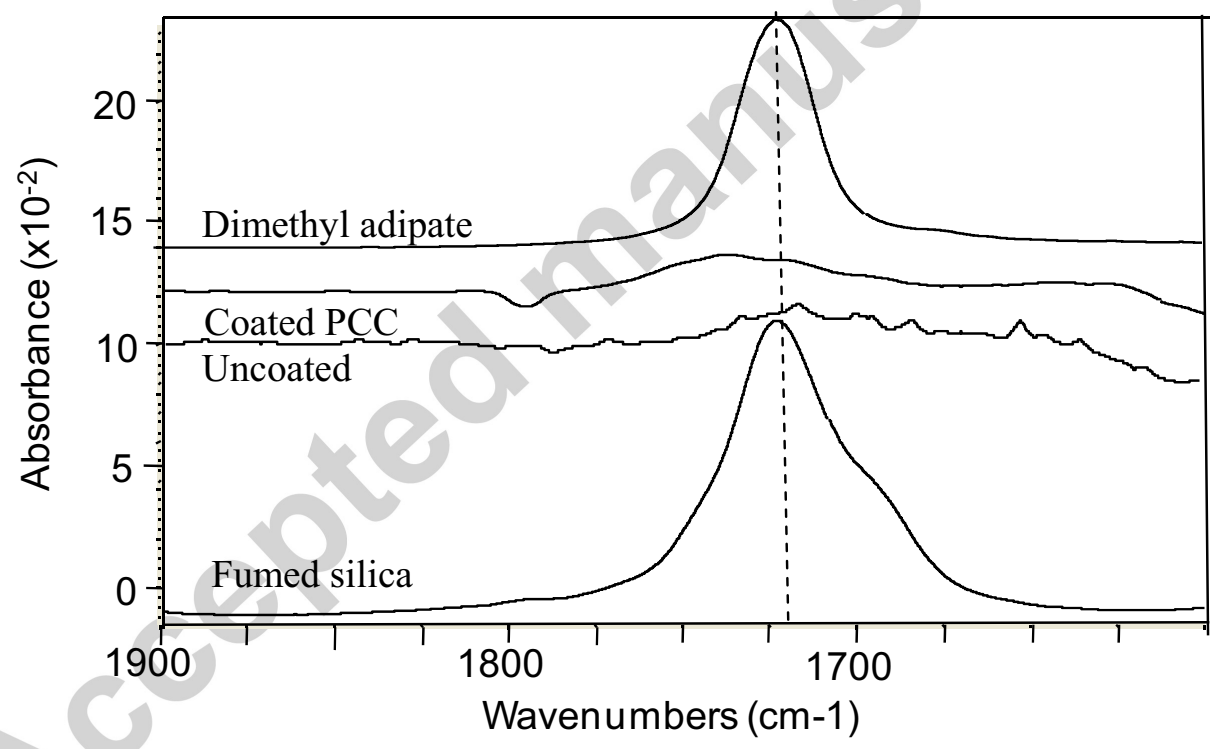

Figure 10 